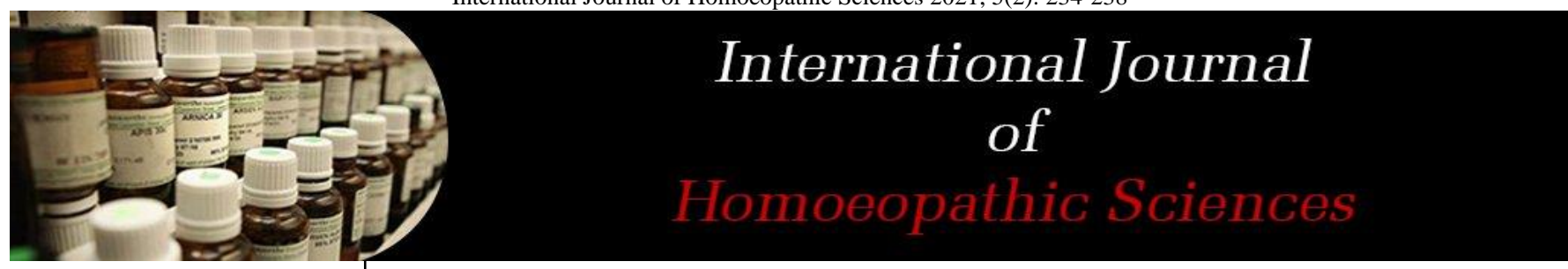

E-ISSN: 2616-4493 P-ISSN: 2616-4485 www.homoeopathicjournal.com IJHS 2021; 5(2): 234-238 Received: 16-02-2021 Accepted: 18-03-2021

Dr. Kaushal Kumar Savera Research Officer (H)/Scientist1, National Homoeopathy Research Institute in Mental Health, Kottayam, Kerala, Under Central Council for Research in Homoeopathy, Ministry of AYUSH, Govt. of India, New Delhi, India

Dr. Ann Maria Rose Junior Research Fellow (H), National Homoeopathy Research Institute in Menta Health, Kottayam, Kerala, Under Central Council for Research in Homoeopathy, Ministry of AYUSH, Govt. of India, New Delhi, India
Corresponding Author: Dr. Kaushal Kumar Savera Research Officer (H)/Scientist1, National Homoeopathy Research Institute in Mental Health, Kottayam, Kerala, Under Central Council for Research in Homoeopathy, Ministry of AYUSH, Govt. of India, New Delhi, India

\section{Management of palmoplantar psoriasis through homoeopathic medicines with more than one year of follow up: A case study}

\author{
Dr. Kaushal Kumar Savera and Dr. Ann Maria Rose
}

DOI: https://doi.org/10.33545/26164485.2021.v5.i2d.388

Abstract

Psoriasis is a chronic immune-mediated skin condition with multiple remissions and relapses. It is characterized mainly by dry itchy skin with scaling, burning sensation and bleeding spots. Conventional treatments include topical steroids, light therapy and oral medications. This paper aims to report a case of palmoplantar psoriasis in a 75- year- old female, presented with symptoms of cracks and excoriation of soles, heel, itching of palms, treated and managed with homoeopathic medicines.

Keywords: homoeopathy, palmoplantar psoriasis, psorinum, sulphur

\section{Introduction}

Psoriasis is a chronic, non-contagious, hyperproliferative skin disorder of multifactorial origin in which certain genetic and environmental factors acts on certain individuals leading to immune dysregulation and abnormal keratinisation resulting in appearance of cutaneous lesions [1]. "Psoriasis" meaning "itch" is derived from a Greek word "Psora" [2]. Psoriasis is characterized by well-defined scaly erythematous plaques, mainly affecting scalp, fingers and toes, palms, soles, umbilicus, gluteus, underneath the breasts and genitals, elbows, knees, shins and sacrum ${ }^{[2,3]}$.

Approximately $2 \%$ of world's population is affected by Psoriasis. ${ }^{4}$ Prevalence of Psoriasis is in ranges between $0.09 \%$ and $11.4 \%$ worldwide and it can affect all age groups, both sexes irrespective of ethnic variations [5]. In India it ranges from $0.44 \%$ to $2.8 \%{ }^{[6]}$. Studies conducted on monozygotic twins suggest $70 \%$ chance of developing psoriasis if the other twin is affected and 20\% chances in case of dizygotic twins ${ }^{[7]}$. Among those with skin psoriasis $10-20 \%$ have psoriatic arthritis and among this $53-86 \%$ are affected with nail changes, pitting ${ }^{[7]}$. In adults prevalence ranges from 0.91 to $8.5 \%$ and in children it is between 0.2 to $1 \%{ }^{[8]}$.

Various clinical forms of psoriasis include, guttate, pustular, flexural, erythrodermic, nail, articular, oral, palmo-plantar and occular forms ${ }^{[9]}$. Main symptoms include dry skin, itching and burning sensation, signs of pustular psoriasis, depression, painful swollen joints and genital lesions ${ }^{[8]}$. Various complications of psoriasis are psoriatic arthritis, eye conditions, cardiovascular diseases, auto immune diseases like celiac disease, IBD, Parkinson's disease, kidney diseases, secondary bacterial infections, protein and electrolyte imbalance. ${ }^{8}$ Main triggering factors include: trauma, intercurrent infection, certain drugs (viz. beta-blockers, anti-malarial drug, lithium etc.), stress/anxiety ${ }^{[3]}$.

Diagnosis of Psoriasis is done by clinical examination based on the appearance and characteristics of skin. Scraping and skin biopsy are at times done to differentiate from fungal infections and other disorders ${ }^{[7,8]}$.

Joint involvements are assessed by radiographic examinations ${ }^{[7]}$. Conventional treatments include topical agents (emollients, corticosteroids, dithranol, tar and deltanoids), Systemic agents, UV phototherapy and dietary management (drink plenty of water, proper and healthy diet) ${ }^{[10]}$.

As per the Homoeopathic philosophy skin diseases are the manifestation of the disarrangement of the internal disorders. If the treatment of the skin disorders are being done by the external or topical agents, suppression caused by this practice leads to damage the more vital internal organs ${ }^{[11,12]}$. Psoriasis is one of the diseases which not only affect the skin alone but involve the other parts of the body also, like joints, cardiovascular, kidney, 
mental spheres etc. ${ }^{[8]}$ Homeopathic medicines when used for this type of disease not only improve the conditions of outer skin but also remove any disturbance appeared in the internal body ${ }^{[9,13,14,15]}$.

\section{Case Report}

\section{Patient Information}

A 75 years old short, fat, obese lady of fair complexion, nurse by profession was presented to the OPD of NHRIMH, Kottayam with the following symptoms:

1. Cracks and excoriation of soles, heels.

2. Severe itching followed by bleeding which are painful.

3. Discharge at times sticky.

4. Hardening of skin of soles.

5. Aggravation early morning, damp weather, cold climate.

6. Itching also over palms, with blackening of skin of palms.

Complaint started 13 years back. First as thickening of skin on soles, followed by cracks in skin with pain while stepping, walking. It followed by severe itching, exfoliation of skin with oozing of bloody discharge and occasionally with sticky discharge. Later cracks appeared more on heels. Itching is more at morning hours and in damp weather. Sometimes this itch even disturbs her sleep. Skin of palms and other parts of body became black due to severe itching. She underwent various treatment procedures for the complaint including external applications. During childhood patient was affected with mumps, chickenpox and hepatitis, also underwent tonsillectomy at the age of 40 and angioplasty at the age of 59. She is known hypertensive with hypothyroidism. She is currently on following medication Tab. Thyroxin, Tab. Aspirin, Tab. Cilacar, Tab. Matrilex, Tab. Candez for Thyroid and Cardiac Abnormalities.

Hermother and siblings (younger sisters) have Psoriasis and son has cardiac complaints. She is having a decreased thirst with a normal appetite preferring non-vegetarian foods and sweets. Bowel habits are regular with urge incontinence. Sleep frequently disturbed due to intolerable itching. On General Examination her BP is $120 / 80 \mathrm{mmHg}$. She is sympathetic and gets angered easily.

The case was diagnosed as Palmoplantar psoriasis based on Clinical presentation and characteristics of Lesion.

\section{Local examination of the Skin}

Site of lesions: Symmetrically over soles and palms predominantly on soles.

Characteristic of skin: Thickened skin with cracks and exfoliation.

Margins: Irregular.

Discharge: Bleeding spots on scratching. Itching: Present.

\section{Analysis of the case}

After careful analysis and evaluation of the case, following symptoms were taken into consideration as totality: -

\begin{tabular}{|c|c|c|}
\hline Symptoms & Corresponding Rubrics & Miasm $^{[\mathbf{1 6}, \mathbf{1 7 ]}}$ \\
\hline Sympathetic & Mind-Sympathetic & Psora* $^{*}$ \\
\hline Easily angered & Mind-Anger easily & Psora* $^{*}$ \\
\hline Desire sweets & Generals-Food and drinks & Psora $^{\#}$ \\
\hline Psoriatic eruptions & Skin -Eruptions- Psoriasis & Psora-Sycosis $^{\#}$ \\
\hline Cracks in feet and soles & Extremities -Cracked skin Feet- Soles, & Psora-Syphilitic $^{\#}$ \\
\hline Cracks in palms & Extremities -Cracked Skin-Hands -Palms & Psora-Syphilitic $^{\#}$ \\
\hline Itching of soles & Extremities -Itching-Feet-Sole of & Psora $^{*}$ \\
\hline Sleeplessness from itching & Sleep- Sleeplessness-itching from & Psora-Syphilitic* $^{*}$ \\
\hline Perspiration over face & Face- perspiration & Sycosis $^{\#}$ \\
\hline Hypertension & Generals -Hypertension & Sycosis $^{\#}$ \\
\hline Hypothyroidism & Generals -Hypothyroidism & Psora* $^{*}$ \\
\hline
\end{tabular}

*: Repertory of Miasm, Patel RP; \#: Miasmatic Prescribing, Banerjea SK.

Repertorization was done using Synthesis Treasureedition 2009v (Schroyans. F), Radaropus 2.2.16, - licence:121347 (Fig. 1). The top five medicines were Sulphur 15/9, Sepia 13/9, Lycopodium 16/8, Psorinum 13/8, Natriummuriaticum $11 / 8$.

On the basis of reportorial analysis and with the help of Materia medica, ${ }^{18}$ Psorinum was selected, as the complaints get worse in winter or cold climate with intolerable itching of lesions. Later Sulphur was prescribed based on reportorial result, when improvement was stopped after initial relief. In between Rhus Toxicodendron was prescribed for presenting acute complaints. The follow up was done for more than 1 years (Table 1 ). 


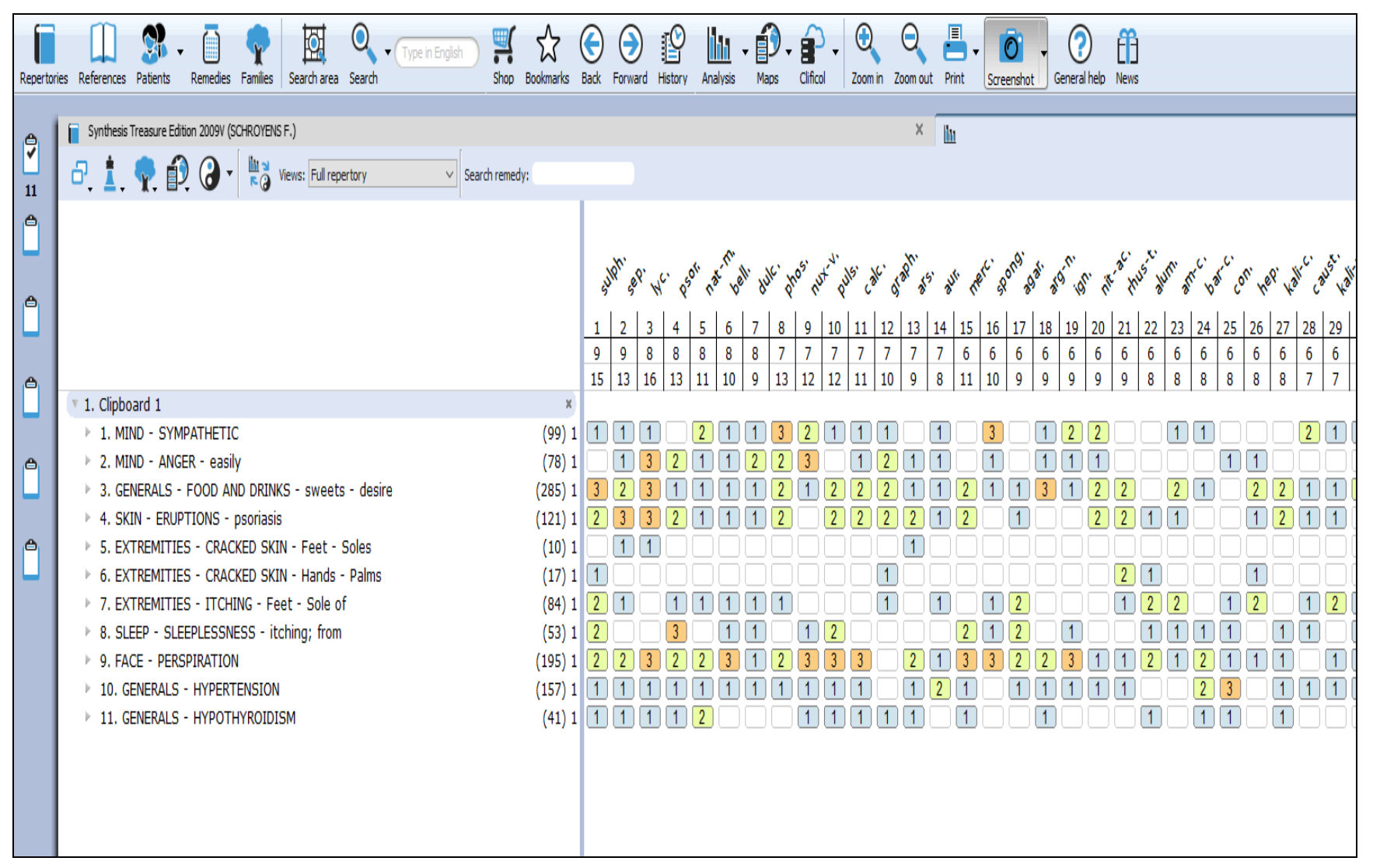

Fig 1: Repertorisation chart

\section{Discussion}

Psoriasis is a chronic hyperproliferative, non-contagious immune mediated disorder affecting $2-3 \%$ of population. Conventional treatment is application of topical steroids, light therapy, and oral medications. In this case patient is suffering from this ailment since last 13 years. Homeopathy considers the patient as a whole which includes physical and mental symptoms along with the symptoms of presenting disease. Prescriptions based on this totality, not only improve the patient symptomatically but also improve the quality of life (QoL). This case also depicted the improvement in the QoL. This case report shows that homoeopathic medicine can reduce sufferings of the patient affected with psoriasis when well indicated. The remedy was selected on the basis of repertorisation and consulting Homoeopathic Materia Medica. Whereas doses, potency and repetition were done as per homoepathic Philosophy.

Table 1: Follow up and Interventions

\begin{tabular}{|c|c|c|c|}
\hline S. No. & $\begin{array}{c}\text { Date of } \\
\text { Prescription }\end{array}$ & Prescription Based on & Medicine Prescribed \\
\hline 1 & 28.10 .2019 & $\begin{array}{c}\text { Psoriatic eruptions of skin, Itching of soles, sleeplessness } \\
\text { from itching <cold }\end{array}$ & $\begin{array}{c}\text { Psorinum 200/2Dose, OD for 2 days } \\
\text { Followed by Sac lac }\end{array}$ \\
\hline 2 & 9.12 .2020 & Symptoms showed partial improvement & Sac Lac was prescribed for a month \\
\hline 3 & 14.01 .2020 & $\begin{array}{c}\text { Itching of lesions aggravated with pain. } \\
\text { Coryza and nasal obstruction since 1 week }\end{array}$ & $\begin{array}{c}\text { Sulphur 200/2Dose, OD for 2 days } \\
\text { Followed by Sac lac }\end{array}$ \\
\hline 4 & 12.02 .2020 & $60 \%$ relief for itching and drawing pain & Sac Lac was prescribed for a month \\
\hline 5 & 20.03 .2020 & Cough with white expectoration since 2 days. Itching <night & Rhustoxicodendron 30/4doses BD for 2 days \\
\hline 6 & 12.05 .2020 & Symptoms show improvement & Sac Lac was prescribed for a month \\
\hline 7 & 18.06 .2020 & Symptoms show improvement & Sac Lac was prescribed for a month \\
\hline 8 & 09.07 .2020 & $\begin{array}{c}\text { Itching and exfoliation of skin of soles slightly increased } \\
\text { with bleeding spots. }\end{array}$ & $\begin{array}{c}\text { Sulphur 200/2Dose, OD for 2 days } \\
\text { Followed by Sac Lac for one month }\end{array}$ \\
\hline 9 & 20.08 .2020 & Symptoms show improvement & Sac Lac was prescribed for a month \\
\hline 10 & 27.10 .2020 & Cracks and exfoliation over heels with itching & $\begin{array}{c}\text { Psorinum 200/1Dose was prescribed } \\
\text { followed by Sac lac for a month }\end{array}$ \\
\hline 11 & 22.12 .2020 & Symptoms show improvement & Sac Lac was prescribed for a month \\
\hline 12 & 29.01 .2021 & Symptoms show improvement & Sac Lac was prescribed for a month \\
\hline
\end{tabular}




\section{Follow-up Assessment}

Dermatology Life Quality Index (DQLI)

DQLI Scores were assessed for the patient from registration (28.10.2019) onwards once in 3 months till January 2021. DQLI Improved to 1 from 12 .

\begin{tabular}{|c|c|c|c|c|c|c|c|}
\hline S. No. & Questionnaire & 28.11.2019 & 14.01 .2020 & 20.04 .2020 & 09.07 .2020 & 27.10 .2020 & 29.01 .2021 \\
\hline 1 & $\begin{array}{c}\text { Over the last week, how itchy, sore, painful } \\
\text { or stinging has your been? }\end{array}$ & 3 & 3 & 2 & 1 & 1 & 1 \\
\hline 2 & $\begin{array}{c}\text { Over the last week, how embarrassed or } \\
\text { self- conscious have you been because of } \\
\text { your skin? }\end{array}$ & 2 & 2 & 1 & 1 & 1 & 0 \\
\hline 3 & $\begin{array}{c}\text { Over the last week, how much has your skin } \\
\text { interfered with going shopping or looking } \\
\text { after your home or garden? }\end{array}$ & 1 & 1 & 1 & 1 & 0 & 0 \\
\hline 4 & $\begin{array}{l}\text { Over the last week, how much has your skin } \\
\text { influenced the clothes you wear? }\end{array}$ & 0 & 0 & 0 & 0 & 0 & 0 \\
\hline 5 & $\begin{array}{l}\text { Over the last week, how much has your skin } \\
\text { affected any social or leisure activities? }\end{array}$ & 1 & 1 & 1 & 0 & 0 & 0 \\
\hline 6 & $\begin{array}{l}\text { Over the last week, how much has your skin } \\
\text { made it difficult for you to do any sport? }\end{array}$ & 0 & 0 & 0 & 0 & 0 & 0 \\
\hline 7 & $\begin{array}{l}\text { Over the last week, has your skin prevented } \\
\text { you from working or studying? } \\
\text { If No, over the last week how much has you } \\
\text { skin been at work or studying? }\end{array}$ & 1 & 1 & 1 & 0 & 0 & 0 \\
\hline 8 & $\begin{array}{l}\text { Over the last week, how much has your skin } \\
\text { created problems with your partner or any } \\
\text { of your close friends or relatives? }\end{array}$ & 2 & 2 & 1 & 1 & 1 & 0 \\
\hline 9 & $\begin{array}{l}\text { Over the last week, how much has your skin } \\
\text { caused any sexual difficulties? }\end{array}$ & 0 & 0 & 0 & 0 & 0 & 0 \\
\hline 10 & $\begin{array}{l}\text { Over the last week, how much of a problem } \\
\text { has the treatment for your skin been, for } \\
\text { example by making your home messy, or by } \\
\text { taking up time? }\end{array}$ & 2 & 1 & 1 & 1 & 0 & 0 \\
\hline & Total Score & 12 & 11 & 8 & 5 & 3 & 1 \\
\hline
\end{tabular}

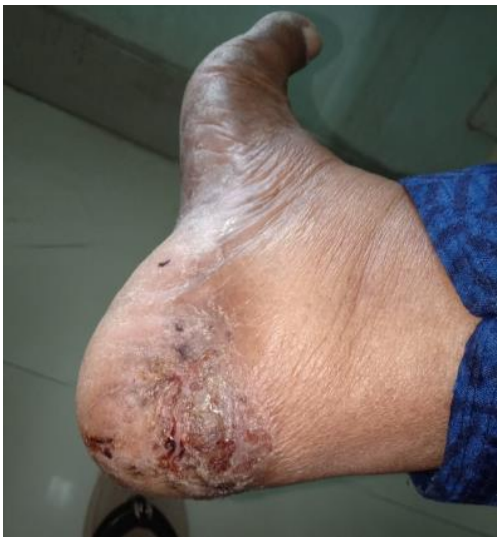

Fig 2: Before Treatment (Right Foot)

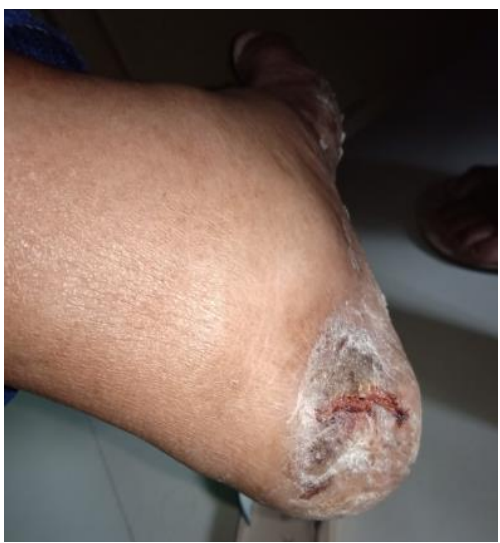

Fig 3: Before Treatment (Left Foot)

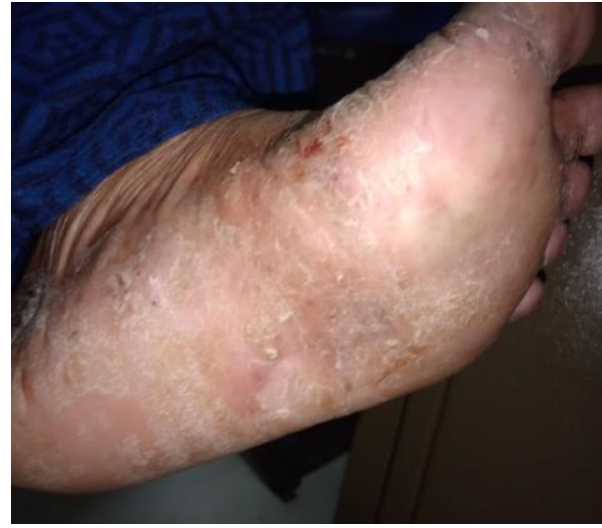

Fig 4: Before Treatment (Left Foot)

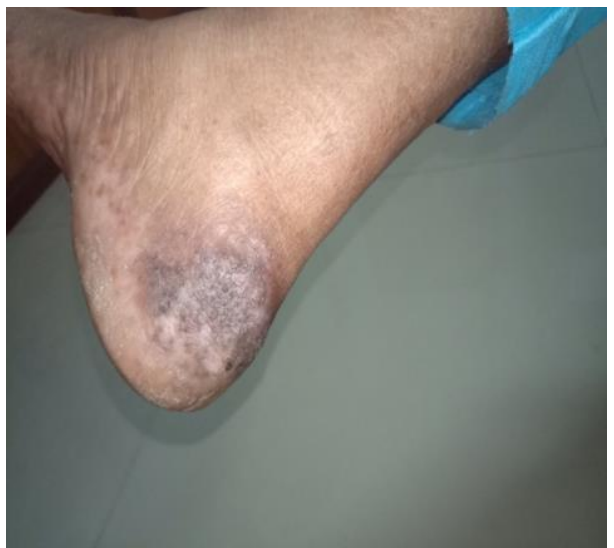

Fig 5: After Treatment (Right Foot) 


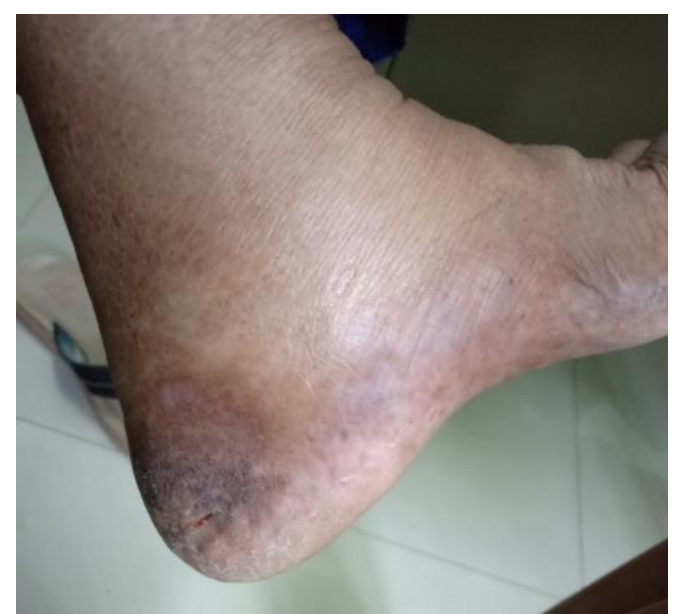

Fig 6: After Treatment (Left Foot)

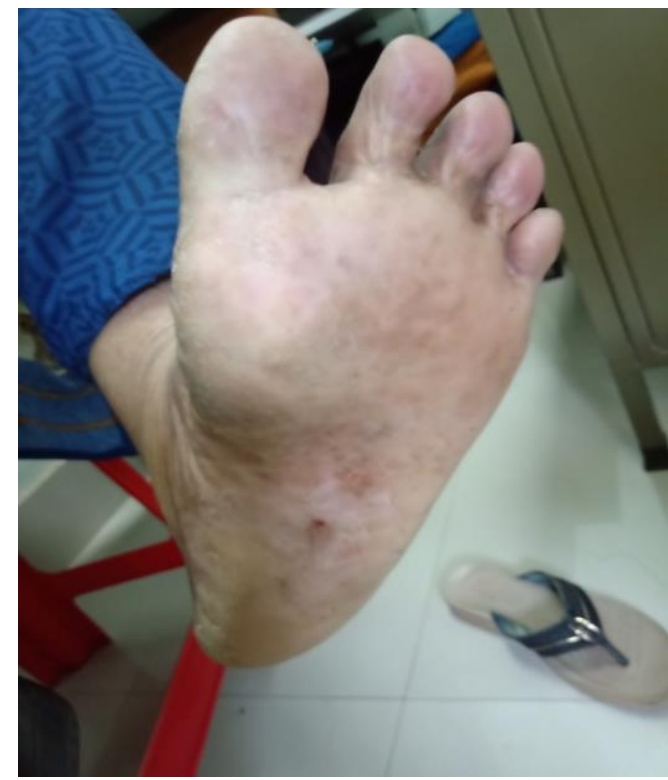

Fig 7: After Treatment (Left Foot)

\section{Conclusion}

Psoriasis can take many forms and palmoplantar psoriasis is one among its various types. This case shows that through homoeopathy we can give relief to clinical symptoms as well as general restoration of health of the patient. However, a well-planned study with large sample size is required to establish the efficacy of homoepathy in psoriasis cases.

\section{Consent}

Consent of the patient was obtained.

\section{Declaration of patient consent}

The authors certify that they have obtained appropriate patient consent form. In the form, the patient has given her consent for her images and other clinical information to be reported in the journal. The patient understands that her name and initials will not be published and due efforts will be made to conceal her identity, but anonymity cannot be guaranteed.

\section{Financial support and sponsorship Nil}

\section{Conflicts of interest}

None declared

\section{References}

1. Ghosh A, Panda S. Recent understanding of the etiopathogenesis of psoriasis. Indian Journal of Paediatric Dermatology. 2017;18(1):1. DOI: 10.4103/23197250.195569

2. Sharma B. Homeopathy medicine for treatment of psoriasis. International Journal of Homoeopathic Sciences 2018;2(4):17-19.

3. Innes JA. Davidson's essentials of medicine. 2nd ed. London, England: Churchill Livingstone 2015.

4. Ogawa E, Sato Y, Minagawa A, Okuyama R. Pathogenesis of psoriasis and development of treatment. The Journal of dermatology. 2018;45(3):26472.DOI: $10.1111 / 1346-8138.14139$

5. World Health Organization. Global Report on Psoriasis. Genève, Switzerland: World Health Organization; 2016.

6. Gupta S, Acharya S, Shanmukha GB, Holla R. A pharmaco-epidemiological study of psoriasis. Int J Basic Clin Pharmacol. 2019;8(11):2475.DOI: http://dx.doi.org/10.18203/2319-2003.ijbcp20194787

7. Kuchekar AB, Pujari RR, Kuchekar SB, Dhole SN, Mule PM. Psoriasis: A comprehensive review. International Journal of pharmacy \& life sciences. 2011;2(6):857-877.

8. Sowmya C, Lavakumar V, Venkateshan N, Anitha P, Senthilnathan B. Current trends in treatment and management of psoriasis: an updated review. Int Res J Pharmacy. 2018;9(3):6-16. DOI: 10.7897/22308407.09336

9. Nwabudike LC. Palmar and plantar psoriasis and homeopathy-Case reports. Our Dermatology Online. 2017;8(1):66.DOI: 10.7241/ourd.20171.18

10. Kumar A, Jindal S, Ashawat MS, Pandit V, Priya V. Psoriasis and Its Treatment: A Review. J. Biol. Chem. Chron. 2019;5(2):28-31. DOI: http://dx.doi.org/10.33980/jbcc.2019.v05i02.004

11. Hahnemann S. The Chronic Diseases, Their Peculiar Nature and Their Homoeopathic Cure. New Delhi: B. Jain Publishers 2009;40(I):98, 101.

12. Nwabudike LC. An introduction to homeopathy for the dermatologist. Dermatology Times. 2019;40;8).https://www.dermatologytimes.com/view/in troduction-homeopathy-dermatologist

13. Nwabudike LC. Psoriasis and homeopathy. Proc Rom Acad Series B. 2011;3:237-42

14. Mahesh S, Shah V, Mallappa M, Vithoulkas G. Psoriasis cases of same diagnosis but different phenotypes-Management through individualized homeopathic therapy. Clinical case reports. 2019;7(8):1499-507.https://doi.org/10.1002/ccr3.2197

15. Witt CM, Ludtke R, Willich SN. Homeopathic treatment of patients with psoriasis-a prospective observational study with 2 years follow-up. Journal of the European Academy of Dermatologyand Venereology. 2009;23(5):538.DOI: 10.1111/j.14683083.2009.03116.x

16. Patel RP. Repertory of Miasm. Kottayam: Hahnemann Homoeopathic Pharmacy; 1996;1(2):429,947,1167.

17. Banerjea SK. Miasmatic Prescribing. New Delhi: B. Jain Publishers (P) Ltd. 2017;162,206,214,230,231.

18. Phatak SR. Materiamedica of homoeopathic medicines. New Delhi: B. Jain Publishers 2002;576-580, 675-682. 